Hispania Sacra, LXII

125, enero-junio 2010, 243-265, ISSN: 0018-215-X

\title{
LA MISIÓN OFICIAL DEL CARDENAL LUIS BELLUGA EN ROMA EN 1722-1723, A TRAVÉS DE UN EPISTOLARIO INÉDITO
}

\author{
POR \\ MARÍA JosÉ VILAR \\ Universidad de Murcia
}

\begin{abstract}
RESUMEN
En el proceso de renovación de la Iglesia española en el siglo XVIII fue fundamental la bula Apostolici Ministerii (1723) de Inocencio XIII, para el exacto cumplimiento de los decretos disciplinares del Concilio de Trento por parte del clero diocesano y del regular. Estaban un tanto postergados hasta el momento. Analizamos los orígenes de ese documento y el decisivo papel que en su negociación, redacción y aprobación tuvo el cardenal Luis Belluga, obispo de Cartagena. Enviado a Roma por Felipe V para la obtención de la bula, permaneció allí los años 1722 y 1723. La fuente básica consultada son los despachos dirigidos por el cardenal Francesco Acquaviva d'Aragona, encargado de negocios de España, a José Grimaldo, Secretario de Estado.
\end{abstract}

PALABRAS CLAVE: Reforma de la Iglesia en España, bula Apostolici Ministerii, Luis Belluga, Francesco Acquaviva, José Grimaldo, Inocencio XIII, Felipe V, siglo XVIII.

\section{THE OFFICIAL MISSION OF CARDINAL LUIS BELLUGA IN ROMA IN 1722-1723, AN APPROACH TO AN UNPUBLISHED COLLECTION OF LETTERS DIPLOMATIC}

\begin{abstract}
In the process of renewal of the Church in the eighteenth century Spanish was instrumental Apostolici Ministerii the Bull (1723) Innocent XIII, which imposed strict compliance with the disciplinary decrees of the Council of Trent, somewhat neglected so far, both the clergy and the diocesan convent. Our contribution explores the origins of that agreement, as well as the decisive role in negotiating,
\end{abstract}


drafting and adoption corresponded to Cardinal Luis Belluga, Cartagena's bishop, highlighted by Philip V in order to obtain a bull in Rome, where he remained throughout the biennium 1722-1723. The basic sources consulted, and we bring offices are led by Cardinal Francesco Acquaviva d'Aragona, charge d'affaires of Spain in the Holy See, Jose Grimaldo, Spanish secretary of State.

KEY WORDS: Reform of the Church in Spain, Bull Apostolici Ministerii, Luis Belluga, Francesco Acquaviva, José Grimaldo, Innocent XIII, Philip V, siglo XVIII*.

Recibido/Received 10-05-2009

Aceptado/Accepted 16-10-2009

En el Ministerio de Asuntos Exteriores (Madrid), Sec. Santa Sede, leg. 284, se halla un expediente con la correspondencia oficial dirigida por el cardenal Francesco Acquaviva d'Aragona, representante de España cerca de la Santa Sede, a don José Grimaldo, marqués de Grimaldo, Secretario de Estado. Son dieciséis despachos fechados entre 14 de febrero de 1722 y 18 de septiembre de 1723 .

La correspondencia detalla la actuación del cardenal Luis Belluga y Moncada, obispo de Cartagena, comisionado por Felipe V para gestionar cerca de Inocencio XIII una bula pontificia para una reforma de la Iglesia en España que posibilitara un exacto cumplimiento de los decretos disciplinares del Concilio de Trento. Objetivo básico de esta larga permanencia, entre mayo de 1721 y junio de 1723, dos años largos, fue acelerar y lograr con su intervención personal esta bula, cuya elaboración había sido encomendada por el Papa a una comisión, a la cual se incorporó el cardenal Belluga.

La documentación revela su importante participación en la redacción del texto definitivo de la Apostolici Ministerii. Hubo que sortear antes muchas reticencias y obstáculos. El documento conocido como Bula bellugana tuvo amplia y duradera proyección en la España del siglo XVIII.

Los documentos nos ilustran sobre otras actuaciones y encargos del obispo de Cartagena, asuntos por lo general relacionados con su diócesis, aunque no exclusivamente. En particular cerca de las Congregaciones de Concilio y Ritos, a las que fue agregado como informante. Se le consideraba buen teólogo y experto canonista, bien preparado para supervisar propuestas, votos razonados, acuerdos y decretos.

\footnotetext{
* ABREVIATURAS UTILIZADAS

AHN: Archivo Histórico Nacional (Madrid)

AMAE: Archivo del Ministerio de Asuntos Exteriores (Madrid)

AOC: Archivo del Obispado de Cartagena (Murcia)

ASV: Archivio Segreto Vaticano (Città del Vaticano)

CSIC: Consejo Superior de Investigaciones Científicas (Madrid)
}

Hispania Sacra, LXII

125, enero-junio 2010, 243-265, ISSN: 0018-215-X 
Para su diócesis de Cartagena, entre otros logros, obtuvo privilegios para los oficios litúrgicos de los cuatro santos cartageneros Isidoro, Leandro, Fulgencio y Florentina, concesiones aplazadas hacía tiempo. Sacó adelante la negociación para el nombramiento de su sucesor, puesto que Felipe V tenía convenido con el Papa que Belluga renunciara a su sede diocesana al término de su misión extraordinaria en Roma, para retornar a Italia como cardenal de la Curia, como así fue. ${ }^{1}$

\section{Francesco Acquaviva D’Aragona y José Grimaldo}

El autor de la serie documental aquí presentada es Francesco Acquaviva d'Aragona, representante de España cerca de la Santa Sede. Fue embajador, después de haber sido encargado de negocios muchos años. Nacido en Nápoles en 1665 en el seno de antigua familia hispano-napolitana, y por tanto muy vinculada a la Corona española, y sus miembros con la condición de súbditos españoles. Su padre era el XIV duque de Atri.

Habiendo optado Francesco por seguir la carrera eclesiástica, y contando con la protección de Inocencio XI, de quien fue camarero de honor, su sólida formación eclesial y humanista, y el dominio de idiomas, posibilitó su entrada en el servicio diplomático pontificio. Después de desempeñar funciones diversas en Roma, Ferrara y Malta, retornó a la Curia romana como asesor del nuevo papa Inocencio XII, quien lo recompensó por sus servicios con el obispado in partibus de Larissa (1697) y con misiones de confianza en varias nunciaturas. Su definitiva promoción se dejó esperar, sin embargo, al siguiente pontificado, el de Giovanni Francesco Albani, Clemente XI, entre 1700 y 1721, culminando al encomendársele una delicada misión en Madrid en agosto de 1706, siendo ya cardenal desde unos meses antes.

\footnotetext{
${ }^{1}$ Para el conocimiento de la personalidad y obra de Luis Belluga es fundamental la consulta de Juan B. VILAR, El cardenal Luis Belluga. $2^{\mathrm{a}}$ ed. Editorial Comares. Granada. 2005 (1 ${ }^{\mathrm{a}}$ ed.: Granada. 2001), que revisa, amplía y completa las biografías y estudios precedentes, además de remitir a la extensa bibliografía disponible. Sobre el pontificado cartaginense de Belluga inciden también especialmente las actualizadas aportaciones de Antonio IRIGOYEN LÓPEZ, Un obispo, una diócesis, un clero: Luis Belluga, prelado de Cartagena. R. Academia Alfonso X el Sabio. Murcia. 2005, Juan B. VILAR, La obra inédita e impresa del cardenal L. Belluga. Selec. de textos. Clásicos Tavera. Serie IV. Madrid. 2005, y Cristóbal Belda NAVARro (dir.) y GómeZ DE RuEdA, J. (coord.): Luis Belluga y Moncada. La dignidad de la púrpura. Fundación Cajamurcia. Murcia. 2006, así como varios estudios de Francisco Víctor SÁNCHEZ GIL en diferentes revistas italianas y españolas. Y para la actuación posterior del mitrado, aparte la biografía mencionada en primer lugar, puede resultar útil nuestra síntesis: «El cardenal Belluga en Italia», en C. BELdA NAVArRo (dir.) y Gómez DE RuEDA, J. (coord.): Luis Belluga..., op. cit., pp. 317-30.
} 
Como Acquaviva se mostrase decidido partidario de Felipe V durante la Guerra de Sucesión, y por tanto incompatible con las tesis antiborbónicas del papa Albani, optó por recuperar su condición de súbdito español y entrar al servicio de la causa felipista. Privado de sus rentas y beneficios durante la ocupación austriaca del reino de Nápoles, Felipe V le recompensó con el nombramiento de encargado de negocios de España cerca de la Santa Sede. Desempeñó el encargo con el título anejo de Cardenal Protector de España. Como tal le correspondió afrontar las variables relaciones de Madrid con Roma, en general tensas y difíciles durante el pontificado de Clemente XI, hasta llegarse a la ruptura, y a la consiguiente clausura durante un tiempo de la Nunciatura en la capital española.

Sin embargo Acquaviva se mantuvo en todo momento en Roma como encargado de negocios en funciones, por más que su labor resultara especialmente dificultosa y poco compatible con su condición de prelado italiano y con un pasado inmediato especialmente vinculado a la Curia pontificia. Con todo, su gestión fue altamente positiva al limar asperezas y salvar dificultades hasta ver restablecida una relación armónica entre España y la Santa Sede, conveniente para ambas partes. Objetivo alcanzado plenamente tras la muerte de Clemente XI, y la exaltación al trono pontificio sucesivamente de los cardenales Michelangelo Conti y Francesco Piero Orsini, papas Inocencio XIII (1721-1724) y Benedicto XIII (1724-1730), más próximos a España y a su nueva dinastía. Uno y otro favorecieron que Acquaviva permaneciera al frente de la Embajada española en Roma hasta su voluntario retiro en 1724, en que asumió sus funciones el cardenal Cornelio Bentivoglio.

Llegado ese momento Benedicto XIII lo promovió a la sede episcopal de Sabina. Francesco Acquaviva d'Aragona fallecía en 8 de enero de 1725, siendo sepultado en la iglesia romana de Santa Cecilia, de la que era cardenal titular. ${ }^{2}$

El destinatario de los despachos de Acquaviva es José Gutiérrez de Solórzano, marqués de Grimaldo, más conocido como José Grimaldo. Vizcaíno nacido en 1664 y protegido del ministro Jean Orry, sirvió con lealtad y eficacia la causa de Felipe V desde su advenimiento al trono en 1700, siendo promovido cinco años más tarde a una de las secretarías del Despacho.

${ }^{2}$ B. Storace, Istoria della famiglia Acquaviva, reale d'Aragona. (S.i.). Roma. 1738, pp. 86-99; F. Nicolini, «Francesco Acquaviva d'Aragona», en VV.AA., Dizionario Biografico degli Italiani. Istituto della Enciclopedia Italiana. Roma. 1960, vol. I, p. 191ss., quien remite además a la bibliografía existente (L. Cardella, L. Karttunen, P. Litta, G. Moroni, L.V. Pastor, etc.). En cuanto al contexto de las relaciones hispano-pontificias del momento, puede verse en E. PorTILlo, «Estudios críticos de Historia eclesiástica española durante la primera mitad del siglo XVIII», Razón y Fe, a. 1907-1908. Para aspectos más puntuales disponemos de aportaciones posteriores de A. Mestre SANChÍs, J. FERNÁNDEZ Alonso y V. CÁRCEl ORTí, entre otros.

Hispania Sacra, LXII

125, enero-junio 2010, 243-265, ISSN: 0018-215-X 
Grimaldo no tardaría en manifestarse como eficiente gestor, y como hábil político capaz de mantenerse en primera línea en Madrid mediante el desempeño de ese y otros importantes cargos gubernativos durante toda la contienda sucesoria y en la década siguiente (secretarías de Guerra y Hacienda, Marina e Indias, etc.).

Desde 1719 estuvo al frente de la Primera Secretaría de Estado, siendo por tanto el jefe de la diplomacia española, coordinador de las Relaciones internacionales de España y una de las primeras figuras políticas del momento. Funciones todas ellas que sobrevivieron a la caída del valido Juan Guillermo de Ripperdá, a quien sustituyó en colaboración con José Patiño, después de haber figurado en los sucesivos equipos de gobierno encabezados por la princesa de los Ursinos, Michel-Jean Amelot, Melchor Rafael de Macanaz, el abate Giulio Alberoni, el confesor real Daubenton y los ya mencionados Orry y Ripperdá. ${ }^{3}$

El ministro Grimaldo se mantuvo en el poder hasta 1726. Su relevo fue consecuencia de la animadversión de la segunda esposa de Felipe V, la reina Isabel de Farnesio, a cuya política belicista en Italia se oponía el ministro por entender, y no se equivocaba, que respondía a objetivos personales y familiares de la soberana, pero no a los intereses generales de España.

Se debió también ese relevo a presiones e intrigas promovidas desde las cortes de París y Viena, que acusaban a Grimaldo de manifiesta anglofilia. ${ }^{4}$ Sus

\footnotetext{
${ }^{3}$ Sobre José Grimaldo y su actuación, véase Carlos MarTínez Shaw y Marina AlFonso Mola, $\mathrm{Fe}$ lipe V. Arlanza Ediciones. Madrid. 2001, pp. 107-34 y 222-65. Para el contexto internacional de tiempos de Grimaldo y la labor de éste en la conducción de la política internacional de España, así como su contribución al diseño y conformación de un aparato diplomático eficiente, véase: José Antonio EscuDERo, Los secretarios de Estado y del Despacho. Instituto de Estudios Políticos. Madrid. 1969; ID., Los orígenes del Consejo de Ministros en España. CSIC. Madrid. 1979, 2 vols. (vol. I); Didier OzAnam, «La diplomacia de los primeros Borbones (1714-1759)», Cuadernos de Investigación Histórica, V (1982), 169-93; Id., «La política exterior de España en tiempos de Felipe V y Fernando VI», en vol. XXIX de Historia de España fundada por R. Menéndez Pidal y dirigida por J. $M^{a}$ Jover Zamora. Espasa-Calpe. Madrid. 1985, p. 441ss.; José Antonio AMARILLAS, «La política exterior de los primeros Borbones», en J. L. Comellas y J. Andrés GAlLeGo (dirs.), La España de las Reformas, t. X-2 de Historia General de España y América. Ed. Rialp. Madrid. 1984, pp. 267-98. Todos ellos remiten a una amplia y actualizada bibliografía sobre la temática de referencia.

${ }^{4} \mathrm{M}^{\mathrm{a}}$ Ángeles Pérez SAMPER, Isabel de Farnesio, Plaza \& Janés. Barcelona. 2003, p. 212 ss. Véase también, entre otros, Gonzalo ANEs, El Antiguo Régimen. Los Borbones. Alianza Ed. Madrid. 1975; ID., El Siglo de las Luces. Alianza Editorial. Madrid. 1999; Luis Miguel Enciso ReCio (et al.), Los Borbones en el siglo XVIII (1700-1808). Gredos. Madrid. 1991; Agustín GonZÁLEZ EncIso, Felipe V: La renovación de España. Sociedad y economía del primer Borbón. EUNSA. Pamplona. 2003, pp. 74-83 [«El estamento eclesiástico»]; Ildefonso Pulido BuENo, José Patiño: el inicio del gobierno políticoeconómico ilustrado en España. Univ. de Sevilla. Sevilla. 1998; John LYNCH, El siglo XVIII. Ed. Crítica. Barcelona. 1991; Henry Kamen, Felipe V: el rey que reinó dos veces. Temas de Hoy. Madrid. 2000; $\mathrm{M}^{\mathrm{a}}$ Victoria López Cordón, $\mathrm{M}^{\mathrm{a}}$ de los Ángeles Pérez SAmper y Ma Teresa Martínez de SAs, La Casa
} 
funciones fueron absorbidas por Patiño. El alejamiento de Grimaldo fue ya definitivo. Falleció en Madrid en 1733.

\section{CONTENIDO DE LA FUENTE APORTADA}

Los dieciséis despachos de Francesco Acquaviva van desde el 14 de febrero de 1722 hasta el 18 de septiembre del siguiente año. Siguen con detalle la estancia del cardenal Luis Belluga en Roma y sus gestiones para cumplir su misión: un proyecto de reforma de la Iglesia en España ideado por Felipe V y sus consejeros, que tenía el apoyo de una parte del episcopado español, incluido Belluga. ${ }^{5}$

Fue éste quien sugirió al rey, al término de varios intentos reformistas fallidos, la conveniencia de una bula papal que sancionase la reforma y restableciese la disciplina en el clero. Belluga podría gestionar la bula al tener que ir al cónclave para elegir sucesor de Clemente XI, fallecido en febrero de 1721.

Viajó Belluga por mar en compañía del cardenal Carlos de Borja. Llegaron a Civitavecchia a finales de mayo. El nuevo Papa, Inocencio XIII, había sido ya elegido. Con él siguió Belluga las gestiones, pues el electo, a sugerencia del influyente cardenal Própero Lambertini, futuro Benedicto XIV, era su amigo y lo retuvo en la Curia como miembro de la Congregación del Concilio, encargada de ejecutar la reforma de Trento y vigilar su aplicación en cada diócesis. Los obispos enviaban cada cinco años una «relatio ad Limina», un informe general sobre el estado de sus fieles y el funcionamiento de las instituciones diocesanas.

El Papa quiso aprovechar la acreditada capacidad y experiencia como canonista del español, y tener presente su criterio sobre diferentes cuestiones referidas a la Iglesia en Europa y América, y muy especialmente a España y sus dependencias ultramarinas. ${ }^{6}$ Una subcomisión de la Congregación, de la que era prefecto Lambertini, preparó la bula.

En un despacho del 14 de febrero de 1722, Francesco Acquaviva informó a José Grimaldo sobre este asunto. ${ }^{7}$ Le comunicó que había recibido una carta de Felipe V para el Papa, «... encomendando y pidiendo a S. Santidad atienda las instancias que hace el Sr. Cardenal Belluga sobre diferentes puntos qe. interesan al mayor bien de la Iglesia por mirar a la disciplina eclesiástica de estos Reynos».

de Borbón. Alianza Editorial. Madrid. 2000, 2 vol. (vol. I; Ricardo GARCíA CÁRCEL, Felipe V y los españoles. Una visión periférica del problema de España. Plaza \& Janés. Barcelona. 2002.

${ }^{5}$ AHN, Santa Sede, leg. 253, AMAE, Santa Sede, legs. 171, 284-285; ASV, Cod. Vat. lat. 9.794, fs. 292r-308r: Cardinalis Bellugae.

${ }^{6}$ J. B. VILAR, El cardenal Luis Belluga..., op. cit., p. 282-83.

${ }^{7}$ AMAE, Santa Sede, leg. 284: F. Acquaviva a J. Grimaldo, Roma 14 febrero 1722. 
El negocio estaba en marcha, dado que la comisión correspondiente se hallaba constituida y funcionando «... siendo S. Em[inenci]a mismo uno de los miembros que componen la Congregación particular de Cardenales, a quienes esta materia está cometida, y que continuamente se va juntando por este negocio».

Sus miembros se hallaban bien dispuestos para atender las pretensiones de la Corona de España manifestadas por Belluga, aunque acaso no en los términos sugeridos por el cardenal español, a quien el propio Acquaviva consideraba demasiado perfeccionista: «...enamorado de lo más perfecto», refiere. En suma, se trataba de acelerar la elaboración de la bula, presionando con la misiva real remitida al pontífice por conducto del encargado de negocios de España.

Una semana más tarde, ${ }^{8}$ habiéndose reunido Acquaviva con Belluga para debatir la carta del monarca, y apremiado aquel por el obispo de Cartagena para que, sin demora, la hiciera llegar al Papa, Acquaviva la entregó al cardenal de Santa Inés, Secretario de Estado, para que, siguiendo el protocolo establecido, llegara a su destino. Transcurrido un mes, el encargado de negocios en Roma daba a conocer la favorable respuesta de Inocencio XIII a Felipe V y otras similares enviadas a diferentes prelados españoles que «... han unido sus súplicas con las del mismo Cardenal [Belluga]». ${ }^{9}$ Sin embargo advertía que los trabajos para la preparación de la bula avanzaban despacio, y «...en forma de no poderse $\mathrm{a}[\mathrm{h}]$ ora terminar».

Transcurrieron cinco meses sin novedad. A la vuelta del verano la negociación se hallaba en punto muerto. Practicadas las indagaciones oportunas, Acquaviva informó a Madrid ${ }^{10}$ que la causa de ello era la cerrada oposición de los religiosos españoles a las propuestas reformistas del obispo de Cartagena. Destacaron en Roma una comisión presidida por los procuradores generales de carmelitas y mercedarios para defender sus tesis. Acquaviva pronosticaba que esa oposición, cuando menos, ralentizaría la puesta en marcha de la reforma.

En diciembre del 1722 nada había avanzado la negociación de un texto satisfactorio para todas las partes implicadas. Sugirió Belluga de centrar la bula en el clero diocesano, al parecer poco o nada reticente, dejando la reforma conventual para más adelante, y de esta forma allanar al principal obstáculo que impedía la puesta en marcha de su plan reformista. La mayoría de los otros cardenales de la subcomisión se opuso. Se aprobó un plazo de un mes para recibir un informe razonado del clero conventual. En él debería explicar su postura. A la vista de ese acuerdo, deseoso Belluga de concluir su misión en Roma, y para ganar tiempo, sometió a la consideración de sus colegas un borrador de bula por

\footnotetext{
8 Ibidem, id.: Acquaviva a Grimaldo, Roma 21 febrero 1722.

${ }^{9}$ Ibidem, id.: El mismo al mismo, Roma 21 marzo 1722.

${ }^{10}$ Ibidem, id.: El mismo al mismo, Roma 12 septiembre 1722.
} 
él redactado, borrador que según informaría Acquaviva a Grimaldo, ${ }^{11}$ pensaba enviar sin demora a España para sondear las opiniones de Felipe $\mathrm{V}$ y sus consejeros, y del episcopado español.

Transcurrido un mes sin novedades sobre la bula, Belluga, prorrogó su estancia en Roma, circunstancia que aprovecharía para tramitar otros asuntos pendientes. Entre ellos la inclusión de san Fulgencio, patrón de la diócesis de Cartagena, entre los doctores de la Iglesia con oficio litúrgico propio, asunto apoyado por Felipe V, deseoso de complacer a Belluga. Para ello envió una misiva a Inocencio XIII, que Acquaviva hizo llegar enseguida al Papa, ${ }^{12}$ y que debió contribuir a la aprobación de esa petición. ${ }^{13}$

En abril de 1723, teniendo la Congregación del Concilio concluido el texto de la bula, en términos bastante acordes con el borrador del cardenal Belluga, cambiaron desfavorablemente las circunstancias de las que dependía su aprobación. Inocencio XIII se mostró reticente. Se inclinaba por soluciones alternativas menos expeditivas, vista la cerrada oposición no solo del clero regular casi en bloque, sino también «... de muchos Obispos de España que creen perjudizial a su decoro -informará Acquaviva a Grimaldo, transcribiendo palabras del Papa en una reciente entrevista que tuvo con él sobre el asunto- ${ }^{14}$ el que se diga que sus Diocesanos necesitan reformas y nuebas Bullas para la execución del conzilio de Trento, quando ellos creen que en todo se cumple con la mayor exactitud, y han llegado a decir que, si este Sr. Card ${ }^{1}$. Belluga tiene esta necesidad en su Diócesis, bien lo puede remediar por sí mesmo, [como] lo hazen los demás sin passar a estas novedades tan ruidosas».

Pese a tantas dificultades, Belluga tenía la firme convicción de que el Papa aprobaría la bula de forma inmediata, pues sus reticencias eran más aparentes que reales, y buscaban satisfacer siquiera mínimamente a quienes no estaban de acuerdo con el documento. No obstante, la opinión general desautorizaba la de Belluga, incluida la del encargado de negocios español en Roma, quien entendía, según refirió a Grimaldo en uno de sus despachos, ${ }^{15}$ que cuando menos habría que esperar, o acaso elPapa optase finalmente aprobarlo mediante un breve confirmatorio de los acuerdos de la Congregación, siempre recurrible por las partes interesadas, pues una bula no admitía recurso.

El 3 de mayo Inocencio XIII suscribió la Apostolici Ministerii siguiendo el borrador del cardenal Belluga. Este hecho evidenciaba su indudable ascenden-

\footnotetext{
11 Ibidem, id.: El mismo al mismo, Roma 5 diciembre 1722.

12 Ibidem, id.: El mismo al mismo, Roma 9 enero 1723.

13 Sacra/Congregatione/Rituum/ (...). Concessionis, et approbationis Officii propii/ S. Fulgenti /Episcopi Carthaginen (...). Romae. MDCCXXII.

${ }^{14}$ AMAE, Santa Sede, leg. 284: F. Acquaviva a J. Grimaldo, Roma 10 abril 1723.

15 Ibidem, id.: El mismo al mismo, Roma 8 mayo 1723.
} 
cia sobre el pontífice y sus colaboradores inmediatos. Feliz por su éxito, se dispuso a volver a España para entregarla personalmente a Felipe V. En su informe a Grimaldo, se mostraba atónito Acquaviva, ${ }^{16}$ a quien se había escapado la negociación paralela que, sin duda, el obispo de Cartagena venía realizando con total reserva cerca del Papa y de sus asesores. Anunció que Belluga llevaba a Felipe V informes de la Santa Sede en relación con el proceso incoado al cardenal Giulio Alberoni, ex-ministro universal y valido del monarca español, caído en desgracia, exiliado de España, perseguido también por Inocencio XIII y refugiado en Venecia.

Parece que el asunto Alberoni, en que ambas Cortes, la española y la pontificia, mantenían tesis similares, contribuyó al feliz desenlace de la misión del cardenal Belluga.

Dos días después de promulgarse la bula, Belluga emprendió el regreso a España, llevando consigo el texto original. Erró Acquaviva creyendo que era un breve. Envió copia a Grimaldo. El cardenal también se hizo cargo de los tres toisones de oro y otros objetos valiosos que perteneciesen a los difuntos agentes de España Domingo Acquaviva, Marcelo César Grimaldi y al príncipe de Palestrina, objetos reclamados a los herederos de aquellos por la Corona española.

El viaje de regreso del cardenal fue lento, por causa, según refiere Acquaviva, «... de un achaque en una pierna, $\mathrm{q}^{\mathrm{e}}$. muchíssimo le molesta quando va en coche» ${ }^{17}$ Con esta dolencia hubiera resultado más lógico embarcarse en Civitavecchia, principal salida de Roma al mar, activo puerto mercantil muy bien comunicado con el exterior y en donde España tenía abierto un consulado. ${ }^{18}$

Belluga hizo la ruta terrestre Roma-Génova, donde embarcó para Alicante. Ruta mucho más larga y penosa que la otra, cuyo recorrido le llevó cuatro semanas, del 20 de mayo al 19 de junio, debido a su enfermedad y al mal tiempo. Posiblemente esa elección le fue aconsejada desde Madrid. Pudo pesar en ello el no querer embarcar estando enfermo y recibir en Italia correspondencia oficial que venía de camino desde España, y dejar cerrados varios asuntos. Entre otros, la favorable disposición del monarca y el Papa para aceptar su propuesta de renuncia al obispado de Cartagena, que formalmente tendría lugar el 9 de diciembre del mismo año. ${ }^{19}$

16 Ibidem, id.: El mismo al mismo, Roma 15 mayo 1723.

${ }^{17}$ Ibidem, id.: El mismo al mismo, Roma 22 mayo 1723.

${ }^{18}$ Con ocasión de esta primera estancia de Belluga en Italia asumía las funciones de cónsul de España en Civitavecchia cierto Francesco Malacrosta, comerciante local separado del cargo por irregularidades años más tarde -agosto de 1731- a instancias del cardenal Bentivoglio, encargado de negocios de España ante la Santa Sede. Vid. Jesús PRAdell NAdAl, Diplomacia y comercio. La expansión consular española en el siglo XVIII. Universidad de Alicante - Inst. «J. Gil Albert». Alicante. 1992, p. 130.

19 J. B. VILAR, El cardenal Luis Belluga..., op. cit., p. 288. 
Antes de embarcarse para España, supo también que Felipe $\mathrm{V}$ acogió bien su sugerencia para que designara sucesor en su sede a José Herrero y Humanes, canónigo doctoral de la catedral murciana, propuesta no confirmada por Roma, acaso por reticencias de la Santa Sede, del propio interesado o de ambos, en relación con las cláusulas económicas incluidas por Belluga en su renuncia, de modo que se le asegurara una holgada congrua para mantenerse de por vida, y garantizar la permanencia de sus Pías Fundaciones establecidas en las diócesis de Cartagena y Orihuela. ${ }^{20}$ El Papa, según manifestó al agente Acquaviva en una entrevista, juzgó esas condiciones excesivamente gravosas. ${ }^{21}$

Fue propuesto Tomás José de Montes, granadino como Belluga y amigo personal suyo. De él dice Acquaviva, «... actualmente se halla aquí penitenziado de reclusión en un convento».22 Por tanto poco o nada tenía que perder. A instancias de Belluga, Montes aceptó ser propuesto y luego también la preceptiva confirmación pontificia. Pudo volver a España como obispo en ejercicio, y no a su antigua diócesis de la que fuera apartado. En Murcia, tras tomar posesión, intentaría, aunque sin éxito, una revisión de las onerosas condiciones económicas impuestas por Belluga, con quien mantuvo durante años una relación epistolar fría y tensa. ${ }^{23}$

Entregada la bula al Rey, el cardenal retornó a Roma. Allí asumió destacadas funciones en las Congregaciones del Concilio, de los Obispos, Regulares, de Inmunidades, y muy especialmente en las de Ritos y Propaganda Fide. Realizó misiones diplomáticas importantes. Desempeñó por un tiempo la Secretaría de Estado. Tuvo relación con la Monarquía española y sus dominios ultramarinos en su condición de «Cardenal Protector de España» desde 1726, y desarrolló una labor publicística y cultural importante. Murió en Roma en 22 de febrero de 1743.

${ }^{20}$ AMAE, Santa Sede, leg. 284: Acquaviva a Grimaldo, Roma 5, 12 y 19 junio 1723.

${ }^{21}$ Ibidem, id.: El mismo al mismo, Roma 26 junio 1723.

${ }^{22} \mathrm{M}^{\mathrm{a}}$ José VILAR, «Tomás José de Montes, obispo de Cartagena, contra las Pías Fundaciones del cardenal Belluga», Anales de Historia Contemporánea, Univ. de Murcia, 21 (2005), 221-42; ID., «El cardenal Belluga y la catedral de Murcia. Su aportación financiera desde Italia para su restauración y para los trabajos de cimentación del actual imafronte de la fachada principal», Carthaginensia, vol. XIX (Murcia, 2003), 405-24; Juan B. VILAR, «Memorial jurídico de Tomás J. de Montes, obispo de Cartagena, sobre obligaciones económicas del cardenal L. Belluga para con su antigua diócesis y respuesta de Belluga desde Italia (1736)», Anales de Historia Contemporánea, Univ. de Murcia, 21 (2005), 243-66.

${ }^{23}$ AOC, Sec. 5, caja 1: Correspondencia entre el cardenal Belluga y el obispo Tomás José de Montes, 1736-1737. 


\section{APENDICE DOCUMENTAL}

1. El cardenal Luis Belluga, comisionado por Felipe V, gestiona en Roma cerca del papa Inocencio XIII una Bula pontifica en pro de una reforma de la Iglesia en España que posibilitase un exacto cumplimiento de los decretos disciplinares tridentinos. El pontífice tenía designada una Congregación especial de cardenales para la elaboración de las resoluciones que sirvieran de base a la Bula. El cardenal napolitano Francesco Acquaviva d'Aragona, encargado de negocios de España cerca de la Santa Sede, informa al marqués de Grimaldo, secretario de Estado, sobre las deliberaciones de la Congregación, muy influida por Belluga, si bien dudaba de que los acuerdos de aquella pudieran ser aplicados en su totalidad por resultar excesivamente rigoristas (febrero, 1722). ${ }^{24}$

«Roma y Febrero 14, de 1722.

Con el despacho de 16 de Henero me remite V[uestra] Exc[elenci]a una carta que el Rey, Dios le guarde, escribe al $\mathrm{Papa}^{25}$ encomendando y pidiendo a $\mathrm{S}[\mathrm{u}]$ Santidad atienda las instancias que haze el Sr. Cardenal Belluga sobre diferentes puntos $\mathrm{q}^{\mathrm{e}}$. interesan al mayor bien de la Iglesia por mirar a la disciplina eclesiástica en estos Reynos, y me manda S[u] Em[inenci]a entregar al Papa esta carta, y procurar la buena dirección de esta dependencia -sic-, q $\mathrm{q}^{\mathrm{e}}$. tanto conviene a la Iglesia y al Reyno.

Lo que executaré con la mayor eficacia y con la dirección del mismo Sr. Cardenal Belluga, creiendo q . S. Em ${ }^{\mathrm{a}}$. quede contento de la disposizión qe aquí se va dando a estas dependencias - sic- ${ }^{26}$ siendo $\mathrm{S}$. Em ${ }^{\mathrm{a}}$. mismo uno de los miembros que componen la Congregación particular de Cardenales, ${ }^{27}$ a quienes esta materia está cometida, y que continuamente se van juntando por este negocio. Sin embargo, a lo que me han dicho los de esta Congregación, todo lo que pide este Cardenal es muy justo y muy sancto, pero con tanto rigor a la letra del sagrado Concilio de Trento, $\mathrm{q}^{\mathrm{e}}$. es más para dessearse que para mandarse, y más para alabar [a] los qe. le procuran, qe para reprender [a] los qe no llegan a conseguirlo; y además ha declamado tanto S. Em ${ }^{\mathrm{a}}$. sobre la poca doctrina del clero secular, y los inconvenientes $\mathrm{q}^{\mathrm{e}}$. cree en los Regulares, qe. si todos fuessen assí, mal concepto se haría de la Nazión, pero todo esto se debe al gran zelo de

\footnotetext{
${ }^{24}$ AMAE, Santa Sede, leg. 284: El cardenal F. Acquaviva d'Aragona a José Grimaldo, secretario de Estado y del Despacho, Roma 14 febrero 1722.

25 Inocencio XIII (1721-1724).

26 Asuntos.

${ }^{27}$ Presidida por el cardenal Próspero Lambertini (futuro Benedicto XIV), amigo de Belluga.
} 
S. Em ${ }^{\mathrm{a}}$, tan enamorado de lo más perfecto. En fin, todo lo que resultará de mis diligencias lo participaré a V. Exc ${ }^{\mathrm{a}}$. en execución de la Real orden.

Dios guarde a V. Exc ${ }^{a}$. m[ucho]s a[ño]s como desseo».

2. A instancias de Belluga, el cardenal Acquaviva tramita sin demora la carta enviada por Felipe V a Inocencio XIII instando una Bula pontificia para la reforma de la Iglesia en los dominios españoles (febrero, 1722).28

«Roma y Febrero 21, de 1722.

Habiendo conferido -sic-29 con el Sr. Cardenal Belluga la carta del Rey que V. Exc ${ }^{a}$. me remitió junta a la suya de 16 de Henero, para que Yo insistiese con el Papa para la solícita expedición del negocio que sigue, ha creido S. Em ${ }^{a}$. conveniente que no se pierda tiempo en entregar esta carta para que S. Santidad interponga su autoridad en su despacho, y aunque por el estado $\mathrm{q}^{\mathrm{e}}$. este negocio tiene no me parecía tan precisa esta instancia, sin embargo para satisfacer a los deseos del Sr. Cardenal y con el dictamen de S. Em ${ }^{a}$, he puesto la carta en manos del Cardenal de Sta. Inés, Secretario de Estado, para que luego la passe a las de S. Santidad, y assí estaremos viendo los efectos de estas insinuaciones, que no dudo serán muy conformes a los deseos del Sr. Cardenal Belluga quando no se pida más que el despacho [de los acuerdos] que dependen de la Congregación de Cardenales que entiende en este negocio.

Dios guarde a V. Exc ${ }^{a} \cdot m^{s} . a^{s} . »$.

3. Acquaviva remite a Madrid la pronta respuesta del pontífice. Advierte sin embargo a Grimaldo que los trabajos para la preparación de una Bula avanzaban despacio (marzo, 1722).30

«Roma y Marzo 21, de 1722.

Habiéndose servido el Papa responder a la carta qe. el Rey Ntro. Sor. escrivió sobre las dependencias que está siguiendo en esta Corte el Sr. Cardenal de Belluga, y habiéndomela S. Santidad hecho entregar, adjunto la remito con su copia, para qe. se sirva pasarla V. Exc ${ }^{\mathrm{a}}$. a las manos de S.M.

${ }^{28}$ AMAE, Santa Sede, leg. 284: Acquaviva a Grimaldo, Roma 21 febrero 1722.

${ }^{29}$ Examinado.

30 AMAE, Santa Sede, leg. 284: Acquaviva a Grimaldo, Roma 21 marzo 1722.

Hispania Sacra, LXII

125, enero-junio 2010, 243-265, ISSN: 0018-215-X 
También ha respondido el Papa a esos Sres. Arçobispos de España, que con sus cartas particulares han unido sus súplicas con las del mismo Sr. Cardenal, cuyo principal negocio se continúa a tratar en la Congregación particular, a la qual S. Santidad lo tiene remitido, aunque [el asunto va] mui despacio, y en forma de no poderse $\mathrm{a}[\mathrm{h}]$ ora terminar.

Dios..., etc.».

4. Cerrada oposición de los institutos religiosos españoles a las propuestas reformistas de Belluga en materia disciplinar. Aquellos destacan en Roma a los procuradores generales de carmelitas y mercedarios para defender sus tesis. Acquaviva pronostica que tal rechazo, cuando menos, ralentizaría la puesta en marcha de la pretendida reforma (septiembre, 1722).31

«Roma y Septiembre 12, de 1722.

Tengo entendido que todas las órdenes regulares de España han recurrido al Papa para qe. se le[s] oygan sus razones en [relación con] las proposiciones a la Sancta Sede por el Sr. Cardenal de Belluga, en qe. ellos se interesan, o por sus leyes o sus costumbres, haviendo sido los Diputados [de aquellas] el Procurador General de los Carmelitas, y el de los Mercedarios, pero con papel firmado de todos los demás, pidiendo que se les oy[g]a lo que ellos tienen que representar antes $\mathrm{q}^{\mathrm{e}}$. la Sede Apostólica se empeñe a promulgar leyes formales sobre las susodichas proposiciones hechas por este Sr. Cardenal Belluga; y aunque es cierto que no podrán oponer el que estas sean novedades sino cosas todas determinadas por el Sto. Concilio de Trento y por otras leyes Apostólicas, sin embargo en lo que ellos están en posesión costará mucho trabajo el mandar lo contrario, tratándose solo en materia de disciplina, y aun en cosas que no son de la mayor consideración en la Iglesia. Sin embargo lo cierto será una gran dilazión al despacho de esta materia, [como sucede] quantas vezes salen las partes a contradecir.

Dios..., etc.».

5. La Congregación para la Reforma de la Iglesia en España se opone mayoritariamente a una propuesta de Belluga de centrar la proyectada Bula en el clero diocesano, dejando la reforma del conventual para más adelante, y de esta forma allanar el principal obstáculo que impedía la puesta en marcha de su plan reformista. Pese a aquellas reticencias, deseoso de concluir su mi-

${ }^{31}$ Ibidem, id.: El mismo al mismo, Roma 12 septiembre 1722. 
sión en Roma y para ganar tiempo, Belluga somete a la consideración de los otros cardenales que entendían en el asunto de la reforma un borrador de Bula por él redactado, borrador que según informa Acquaviva a Madrid, proyectaba enviar sin demora a España para sondear las opiniones sobre el mismo de Felipe $V$ y sus consejeros, y del episcopado español (diciembre, 1722). 32

«Roma y Diciembre 5, de 1722.

Dixe a V. Exc ${ }^{a}$. en una de mis cartas de 2 de Diciembre que envié por el [correo] extraordinario, $\mathrm{q}^{\mathrm{e}}$. el Sr. Cardenal Belluga havía mudado de dictamen en quanto [a] volver a essa Corte con la presteza que S. Em[inenci]a havía determinado, por la razón [de] qe haviéndose tenido en el citado día la Congregación de los Cardenales, a quienes están sometidas las instancias qe. S. Em ${ }^{a}$. ha hecho por la reforma del Clero de España, esta no convino en el dictamen de S. Em ${ }^{\mathrm{a}}$. de qe. se abandonasen los artículos qe. tocaban a Regulares, y se procediesse solo a la [re]forma del clero secular. Y assí dieron [de] tiempo a los Regulares un mes para dezidir sus razones, y entre tanto [Belluga] ha manifestado por el servizio de la Congregación a estos Sres. Cardenales la forma de la Bulla-sic- $\mathrm{q}^{\mathrm{e}}$. pretende se pueda despachar para qe. estos Sres. la vean y consideren. Y por quanto pasará algún tiempo antes [de] qe. esto se pueda despachar en planta, supongo qe este Sr. Cardenal Belluga remitirá a S.M. un tanto de ella primero qe. salga, para $\mathrm{q}^{\mathrm{e}}$. vea S.M. si esta será comunmente aceptada y executada por estos Prelados [españoles], pues aunque no sea de Dogma sino de disciplina bueno es qe. también en esta los Prelados de España fueran concordes, como el Rey sabrá determinarlo mucho mejor de lo que Yo sepa pensarlo.

Dios..., etc.».

6. Transcurre un mes y el debate sobre la Bula permanece abierto. Belluga se ve forzado por ello a prorrogar su estancia en Roma, circunstancia que aprovecha para tramitar otros asuntos. Entre ellos la inclusión de san Fulgencio, patrón de su diócesis de Cartagena, entre los doctores de la Iglesia. Tramita una carta que había obtenido de Felipe V para el papa Inocencio XIII en apoyo de esa propuesta (enero, 1723).33

32 Ibidem, id., id., Roma 5 diciembre 1722.

${ }^{33}$ AMAE, Santa Sede, leg. 284: Acquaviva a Grimaldo, Roma 9 enero 1723.

Hispania Sacra, LXII

125, enero-junio 2010, 243-265, ISSN: 0018-215-X 
«Roma y Enero 9, de 1723.

Este $\mathrm{S}$. Cardenal Belluga ha puesto en mis manos una carta del Rey con la qual suplica al Papa por la declaración de Dr. de la Iglesia para $\mathrm{S}^{\mathrm{n}}$. Fulgencio, la qual entregaré en manos de $\mathrm{S}[\mathrm{u}] \mathrm{B}$ [eatitu]d en mi primera audiencia, y si esta tarda la haré passar por manos del Secretario de Estado, según la insinuazión qe. el mismo Sr. Cardenal Belluga me tiene hecha.

Dios... etc.».

7. Meses más tarde, aunque la Congregación correspondiente ya había concluido el texto de la Bula, de forma bastante acorde con el borrador propuesto por Belluga, Inocencio XIII se mostrará reticente a suscribirlo. Antes al contrario, se inclinará por soluciones alternativas menos expeditivas, a la vista de la cerrada oposición a aquella de un amplio sector del clero espanol, tanto conventual como diocesano (abril, 1723). ${ }^{34}$

«Roma y Abril 10, de 1723.

Excitado de las instancias que me ha hecho este Card[ena]l Belluga para suplicar a Su Sant[id]d aun en nombre del Rey, a fin de que se sirviesse mandar despachar quanto antes una Bulla Apostólica que el Sr. Car[dena]l dessea sobre todos los artículos que se han discurrido y concluido en una Congregación particular sobre las reformas del Clero de España, de lo qual el rey está bien informado, por cuanto S[u] Em[inenci]a me ha dicho, he passado con Su Sant ${ }^{d}$. el oficio conveniente valiéndome del nombre de S.M., como V[uestra] Ex[celenci]a en varias occassiones me tiene prevenido, en la audienzia que ayer se sirvió darme, diziéndole que el Sr. Card ${ }^{1}$. Belluga estaba desseando este despacho para bolver a su Iglesia, ${ }^{35}$ y para executar con mayor autoridad lo que aquí la $\mathrm{S}[\mathrm{an}] \mathrm{ta}$ Sede havrá resuelto, conuiniendo a un fin sancto, y tan justo [a] el desseo y la piedad del Rey.

No he conozido en el Papa gran inclinazión en favorecer esta instanzia en los términos que este Sr. Cardl'. está desseando, qe. es mandando la execuzión de lo resuelto con una Bulla, contra la qual nadie puede reclamar si no obtiene preventivamente la facultad que se llama aperitio oris, y me ha dicho con precisos términos que quizá el Rey no haría estas instanzias si hubiessen llegado a su oydos los clamores de los regulares, que han revuelto el Mundo, y las instanzias de muchos Obispos de España que creen perjudizial a su decoro el que se diga que sus Diocesanos necesitan reformas y nuebas Bullas para la execuzión del

\footnotetext{
34 Ibidem, id., Roma 10 abril 1723.

${ }^{35}$ Diócesis de Cartagena.
} 
conzilio de Trento, quando ellos creen que en todo se cumple con la mayor exactitud, y han llegado a dezir que, si este Sr. Card' . Belluga tiene esta nezesidad en su Diócesis, bien lo puede remediar por sí mesmo, [como] lo hazen los demás sin passar a estas novedades tan ruidosas. Sin embargo ha concluido $\mathrm{Su}$ Sant ${ }^{\mathrm{d}}$. el discurso, diziéndome que estaba en ánimo de sacrificar su aplicazión un dia entero en esta dependenzia, pareziéndome a lo qe. he podido sacar de todo el contexto de su discurso que el Papa mandará expedir un Breve confirmatorio de estas resoluziones, como se suele en las demás, con la cláusula de dejar libre el recurso a la mesma Congregazion en casso de controversias, o quando más, una exortazión a los Obispos para que en sus Diózesis remedien tales inconvenientes, si por acasso los haya. De lo que no se si quedará satisfecho el Sr. Card' ., que havrá esperado mucho más en cumplimiento de sus santos y zelosos desseos.

Dios..., etc.».

8. Belluga reitera su intención de retornar de inmediato a España tan pronto obtuviese la anhelada Bula pontifica sobre reforma eclesiástica. El encargado de negocios español en Roma entendía, sin embargo, que tal documento se dejaría esperar, o acaso el papa optase finalmente por un Breve confirmatorio de los decretos de la Congregación, siempre recurrible, que no una Bula sin posible contestación (mayo, 1723). .36

«Roma y Mayo 8, de 1723.

Luego que llegaron las cartas de essa Corte, el Sr. Card' . Belluga ha passado a ver al Cardenal Secrt ${ }^{0}$. de Estado ${ }^{37}$ para pedirle el que notificasse a Su Sant ${ }^{d}$. la determinazion $\mathrm{q}^{\mathrm{e}}$. ha tomado de partir luego para España, solizitando lo más presto que sea posible la audiencia Pontificia de despedida para salir de Roma antes que se acabe la semana que viene, y no dudo que en esto quedará S. Em ${ }^{a}$. satisfecho; pero no se si será en lo demás que pide pues S. Ema ${ }^{\text {a }}$ me ha dicho qe. está en ánimo de no salir de Roma si el Papa no le entrega la Bulla que está solizitando sobre las dependenzias - sic- $q^{\text {e }}$. aquí ha seguido y qe. V. Exc ${ }^{\mathrm{a}}$. no ignora, y cómo el despacho de esta Bulla está más a los principios de lo qe. el Sr. Cardl'. Belluga se ha figurado. Aunque le han dicho qe. Su Sant ${ }^{d}$. está dispuesto en hazerla, yo creo qe. no será tan de prissa, como en efecto tengo por cierto qe. el Papa no quiere dar esta Bulla sino un Breve confirmatorio de los Decretos de

${ }^{36}$ AMAE, Santa Sede, leg. 284: El cardenal Acquaviva a J. Grimaldo, Roma 8 mayo 1723.
${ }^{37}$ Fabrizio Paoluzzi. 
la Congregación, en vigor, de qe queda siempre libre el recurso a la mesma Congregación.

Dios..., etc.».

9. Obtenida de Inocencio XIII la Bula «Apostolici Ministerii» sobre reforma eclesiástica en España (13 mayo 1723), Belluga se dispone a abandonar Roma. El agente español informa de todo ello a Madrid, como también que Belluga era portador de informes para Felipe V facilitados por la Santa Sede sobre el proceso incoado en Roma al cardenal Julio Alberoni, ex-ministro universal y valido del monarca español, exiliado de España, perseguido a su vez por Inocencio XIII y refugiado en Venecia (mayo, 1723). 38

\section{«Roma y Mayo 15, de 1723.}

Haviendo tenido el Sr. Cardl'. Belluga audienzia de despedida del Papa, por la qual está en ánimo de salir de esta Corte la semana que viene, Su Santd. embió a cassa del Card'. a Mons[eño]r Riviera, Secret[ari]o de la Zifra, y Secrt ${ }^{\circ}$. assímismo del Sacro Collegio, juntamente con el Dr. Fioreli, Juez Deputado -sic-, para hazer los autos en la causa del Card' ${ }^{1}$. Alberoni, que con orden de S[u] $\mathrm{B}$ [eatitu]d ${ }^{39}$ dio quenta por menor al $\mathrm{S}^{\mathrm{r}}$. Card ${ }^{\mathrm{l}}$. del estado de este processo, refiriéndole no tan solamente lo que consta por los mesmos autos sino también lo que se puede alegar por la defensa del mesmo Cardl. Alberoni en respuesta de los cargos que se le hazen, insinuando Mons ${ }^{\mathrm{r}}$. Riviera al Cardl . Belluga, de orden del Papa, el que llegando a essa Corte, informe a S.M. del estado que tiene esta dependenzia, y de la dificultad de acabarla con fines correspondientes a su principio. Y para que pueda el Sr. Card'. Belluga executar esta parte con mayor autoridad, se ha servido el Papa hazerle escribir un papel, por vía de la Secretaría de Estado, en el qual se le da este encargo. [Aunque] no dudo qe . el Sr. Card'. Bellluga dará quenta a S.M. de todo esto, sin embargo no he de escusar prevenirlo a V. $\mathrm{Exc}^{\mathrm{a}}$. para que con la mayor antizipazzion tenga el Rey esta notizia.

Dios..., etc.».

10. Belluga emprende el regreso a España, llevando consigo el original de la Bula pontificia, conceptuada erróneamente como Breve por el representante de España cerca de la Santa Sede. Este, por su parte, remitirá copia del

\footnotetext{
${ }^{38}$ AMAE, Santa Sede, leg. 284: El cardenal Acquaviva a J. Grimaldo, Roma 15 mayo 1723.

${ }^{39} \mathrm{El}$ pontífice.
} 
documento a Grimaldo, titular de la española Secretaría de Estado (mayo, 1723). ${ }^{40}$

«Roma y Mayo 15, de 1723.

Saliendo de esta Corte el Sr. Card1․ Belluga, me ha dejado un impresso del Breve Apostólico del Papa sobre la disciplina eclesiástica en essos Reynos de España, $q^{\mathrm{e}}$. adjunto remito a $\mathrm{V}$. $\mathrm{Exc}^{\mathrm{a}}$. por si acasso no hubiesse llegado por otra parte a la notizia del Rey.

Dios..., etc.».

11. Al poco de salir de Roma, y todavía en Italia, Belluga ha de interrumpir su viaje aquejado de fuertes molestias en una pierna. Llevaba consigo tres collares de la Orden del Toisón de Oro y una llave de la Real Cámara, de que fuera depositario el difunto agente de España, príncipe de Palestrina, que contra entrega del correspondiente recibo, Acquaviva le había confiado para su entrega en Madrid. Recibo extendido por Acquaviva a Belluga (mayo, 1723). ${ }^{41}$

«Roma y Mayo 22, de 1723 .

Anteayer salió de esta Corte el Sr. Card'. Belluga, pero aun es incierto si ha de continuar su jornada [h]asta essos Reynos por mar o por tierra, haviéndosele descubierto a $\mathrm{S}$. $\mathrm{Em}^{\mathrm{a}}$. un achaque en una pierna, $\mathrm{q}^{\mathrm{e}}$. muchíssimo le molesta quando va en coche o cossa semejante.

Al mismo Sr. Cardenal, en razón de la orden de V. Exc a . de 19 de Diciembre del año passado, he entregado tres collares del Toysón qe. son los qe. exprime -sic- el adjunto recibo $\mathrm{q}^{\mathrm{e}}$. Su $\mathrm{Em}^{\mathrm{a}}$. me ha otorgado, como assímismo una llave de la Cámara del Rey, qe. era la qe. tenía el difunto Príncipe de Palestrina, y con esto queda enteramente executada la susodicha orden. Y Yo suplico a V.E., a su tiempo, mandarme acusar recibo de estas al[h]ajas qe. por tanto tiempo han estado a mi cargo.

Dios..., etc.».

[Recibo:]

«He recibido del Excmo Sr. Acquaviva y Aragón, Encargado de los negocios del Rey Ntro. Sor. en esta Corte de Roma, tres collares del Tuson-sic- de oro

40 AMAE, Santa Sede, leg. 284: Acquaviva a Grimaldo, 15 mayo 1723.

${ }^{41}$ Ibidem: Acquaviva a Grimaldo, Roma 22 mayo 1723. 
para entregarlos al Excmo. Sr. Marqués D. Joseph de Grimaldo, en execución de la Orden de S. Magd. del 9 de Diciembre de 1722, y estos se han recivido, el primero de los herederos de D. Domingo de Acquaviva, el otro del Marqués D ${ }^{\mathrm{n}}$. Marcelo César Grimaldi, y el otro de los herederos del Príncipe de Palestrina, como también una llave de la Cámara de S. Magd. de este último, en cuya feé he firmado dos [recibos] de este mismo tenor, que valen por uno. En Roma, a 11 de Mayo de 1723. L[UIS] CAR[DENA]L BELLUGA».

12. Habiendo renunciado el cardenal Belluga a la mitra de Cartagena, es aceptada la renuncia por el pontífice y el monarca. Este propone a Roma como sucesor a José Guerrero y Humanes, canónigo doctoral de la misma iglesia. Pero en razón de la ausencia de Belluga y no habiendo llegado todavía a la Curia romana los Reales despachos con la propuesta a favor de Guerrero, el nombramiento queda aplazado (junio, 1723).42

«Roma y Junio 5, de 1723 .

Junto a una de V. Exc ${ }^{\mathrm{a}}$. de 8 de Mayo recibo la $\mathrm{R}^{1}$. Carta de $\mathrm{S}$. $\mathrm{M}^{\mathrm{d}}$. para el Papa, en la qual admitiendo S. Mgd. la renunzia qe. ha hecho en manos de $\mathrm{Su}$ Sant ${ }^{\mathrm{d}}$. el Sr. Cardl'. Belluga de la Iglesia de Murcia (cuio original hallo en la mesma carta), me manda S. Magd. representar a Su Sant ${ }^{d}$. las quatro condiziones en $\mathrm{q}^{\mathrm{e}}$. la $\mathrm{R}^{1}$. clemenzia ha resuelto admitirla, y en el mesmo tiempo la nomina en D. Joseh Guerrero y Humanes, Canónigo Doctoral de la mesma Yglesia, para ocupar la silla episcopal [vacante], pero hallándose ya de muchos dias a esta parte fuera de Roma el Cardenal, de viage a essos Reynos, se le ha despachado luego un extraordinario a Génova, pudiendo ser qe. todavía se halle S. $\mathrm{Em}^{\mathrm{a}}$. en aquel puerto. Y esta dilación no hará daño porque no han llegado aun los $\mathrm{R}^{\mathrm{s}}$. despachos a favor del nominado $\mathrm{D}^{\mathrm{n}}$. Joseph Guerrero, sin los quales no se puede adelantar esta materia. Y, entretanto, antes qe. llegue a V. Exc ${ }^{\mathrm{a}}$. esta, habrá tenido en derechura por la vía de Genova la notizia de la determinación de S. Em ${ }^{\text {a }}$ Y Y por mi parte, de todo lo qe. aquí se ofreciere en esta materia, daré quenta a V. Exc ${ }^{\text {a }}$. con la mayor exactitud.

Dios..., etc.».

${ }^{42}$ Ibidem: Acquaviva a Grimaldo, Roma 5 junio 1723. 
13. Sobre lo mismo (junio 1723).43

«Roma y Junio 12, de 1723.

Teniendo notizia de $\mathrm{q}^{\mathrm{e}}$. este Card ${ }^{1}$. Belluga por causa de sus achaques, no hauía podido continuar tan solícitamente como deseaba su viage a essas partes por tierra, estoy seguro qe el correo qe. de aquí se le despachó con la notizia de hauer el Rey admitido la dimisión a su Yglesia de Murcia para passarla a manos del Papa, hauiéndolo alcanzado en Génova, estará S. Em ${ }^{\mathrm{a}}$. en la total libertad de emprender a esta Corte el viage como mejor le pareziere. Y entretanto qe quedo esperando las respuestas de S. $\mathrm{Em}^{\mathrm{a}}$., no me ha parecido conveniente dar passos por las circunstanzias qe. han de acompañar la susodicha dimisión. Tanto más $\mathrm{q}^{\mathrm{e}}$. [h] asta ahora no han llegado los despachos para executar la nómina del sucesor en la persona de $\mathrm{D}^{\mathrm{n}}$. Joseph Guerrero y Humanes.

Dios guard[e] a V. Exc ${ }^{\text {a }}$ m[ucho]s a[ños] como desseo».

14. Acquaviva supone a Belluga ya embarcado en Génova rumbo a Alicante. Aquel reitera a Grimaldo su intención de no ocuparse de la provisión de la vacante sede episcopal de Cartagena-Murcia en tanto no llegasen a Roma los preceptivos Reales despachos referidos a este asunto (junio, 1723). ${ }^{44}$

«Roma y Junio 19, de 1723.

Con repetidas cartas me ha manifestado el Sr. Card'. Belluga su intención, $q^{e}$. V. Exc ${ }^{\mathrm{a}}$. habrá visto ejecutada mucho antes qe. llegue a manos de V. Exc ${ }^{\mathrm{a}}$. esta carta, qe. sin duda habrá S. Ema . prevenido, creyendo por lo que me dize que a estas horas ya estará embarcado en las galeras de Génova para Alicante. No obstante la notizia que hauía $\mathrm{S}$. Emª . tenido allí de la determinación tomada por el Rey de admitirle la renuncia de la Yglesia de Murcia, suplicándola al Papa con los quatro artículos qe. contiene el despacho de S.M. en fecha 8 de Mayo, suponiendo S. Emª componer con su personal assitencia assí en su Diócesis como en essa Corte todo lo qe. cree preciso para el buen régimen de la Yglesia, y allanar las dudas qe podían encontrarse en la execuzión de las Reales determinaciones con $\mathrm{q}^{\mathrm{e}}$. me previene $\mathrm{S}$. Em ${ }^{\mathrm{a}}$., [acuerdo] el detener la entrega de la renuncia y de la $\mathrm{R}^{1}$. Nómina $[\mathrm{h}]$ asta tanto $\mathrm{q}^{\mathrm{e}}$. yo reziva nuebas órdenes y declaraciones del Rey, como lo executaré, aunque supongo que $[\mathrm{h}]$ asta tanto $\mathrm{q}^{\mathrm{e}}$. el Papa no tenga en la mano esta renuncia con la determinación de admitirla, no podrá essa Nunciatura tomar los informes que se acostumbran para passar a la

${ }^{43}$ Ibidem, id., Roma 12 junio 1723.

${ }^{44}$ Ibidem, id., Roma 19 junio 1723.

Hispania Sacra, LXII

125, enero-junio 2010, 243-265, ISSN: 0018-215-X 
provisión de la susodicha Yglesia de Murcia en persona de D. Joseph Guerrero y Humanes, nombrado por sucesor, y assí queda esta materia suspendida [h] asta tanto $\mathrm{q}^{\mathrm{e}}$. yo reziva las susodichas nuebas órdenes de S.M.

Dios..., etc.».

15. El encargado de negocios confirma el embarque de Belluga para España, e informa de una audiencia que acababa de tener con Inocencio XIII. En ella se trató de las cláusulas económicas incluidas por aquel en su propuesta de renuncia a la sede de Cartagena, al objeto de asegurarse una muy holgada congrua y garantizar la permanencia de sus Pías Fundaciones tras su marcha, condiciones que el pontífice no dudaba en conceptuar como excesivamente gravosas para el sucesor de Belluga en la mitra cartaginense (junio, 1723). 45

«Roma y Junio 26, de 1723.

En la forma que dixe a V. Exc . con mis cartas de 19 del corriente, hauiéndose embarcado en Génova con buen tiempo el Sr. Cardenal de Belluga, supongo que muchos dias antes qe. esta, habrá llegado a essa Corte o a essos Reynos.

Yo debo dezir a V. Exc ${ }^{\mathrm{a}}$. que en la audienzia que tube del Papa el lunes passado, saviendo que el Sr. Cardl . havía informado a Su Sant ${ }^{d}$. por menor de la determinazión del Rey acerca de la dimisión de la Yglesia de Murcia y Cartagena, creí conveniente motivar -sic- algo a Su B[eatitu]d sobre esta dimisión, que se executará quando el Sr. Cardl. habrá obtenido del Rey algunas declaraciones que necesita, creyendo que entretanto era bueno allanar aquí dificultades en casso que se promoviessen. Y en efecto, es bien que sepa el Rey las qe. en el Papa he encontrado.

La $1^{\mathrm{a}}$. [y $2^{\mathrm{a}}$ ] es en quanto a imponer siete mill excudos romanos de pensión sobre esta mitra, además de la tercera parte que se acostumbra. Y estaba Su Sant ${ }^{d}$. tan prevenido de esta dificultad, que me dijo creía no hubiesse tal exemplar en las Yglesias de España, que aunque quedasse por él provista una congrua muy suficiente para pagar pensiones, se havían de emplear los fructos más líquidos de la Mensa episcopal, quedando por él provisto [lo referente a] las cobranzas más dudosas y más expuestas a contingenzias. Yo le respondí que, en quanto a exemplares, el más inminente que yo tenía presente era el del Obispado - sic_-46 de Oviedo, ${ }^{47} \mathrm{q}^{\mathrm{e}}$. actualmente se halla aquí penitenziado de reclusión

\footnotetext{
45 Ibidem, id., Roma 26 junio 1723.

${ }^{46}$ Obispo.

${ }^{47}$ Diócesis de Cartagena.
} 
en un convento, a quien se le han señalado por dispensa del Papa y con consentimiento del Rey, sus alimentos, cargados sobre los frutos de la mesma Yglesia de Oviedo, además de las acostumbradas pensiones, y actualmente se le están pagando. Y en quanto a la demasiada carga que se supone sea impuesta al futuro [prelado] provisto de Murcia, esto se vería quando vendrá el proceso y el consentimiento del mismo provisto; y por lo qe. toca al exemplar de Oviedo, me mandó Su Sant ${ }^{d}$. remitir una memoria de él en manos del Card ${ }^{1}$. Secretario de Estado para considerarlo.

Por lo qe. mira al artículo 3, qe. el Rey propone [a propuesta del prelado dimisionario] de que se confirmen las pías fundaciones hechas por el Sr. Cardenal de Belluga en su Obispado, me dixo Su Sant ${ }^{\mathrm{d}}$. que antes de resolver era preciso verlas, y siempre con la considerazión [de] si serán demasiadas las cargas para el Prelado [entrante].

En quanto al quarto artículo, que es de conceder a Su Ema . la facultad de conferir por ocho meses los Benefizios, según el indulto cardenalizio, Su Sant ${ }^{d}$. se negó absolutamente a conzederlo, diziéndome que ya de mucho tiempo no estaba en uso darse tal indulto a los Cardenales que dejan sus obispados. Y lo comprobó diziéndome que Su Sant ${ }^{\mathrm{d}}$. mesmo, mientras era Cardenal, mudó dos Obispados, y en ninguno de ellos pudo obtener esta grazia qe. solizitó. Presentemente está negada al Cardenal Cusani, que insta para renunciar [a] su Yglesia de Pavía, y al Cardenal Pico de la Mirandola, que haze lo mismo de la de Sinigalla. De forma que por esta parte no veo camino por donde se puedan venzer estas dificultades, y assí he creido conveniente el que el Rey quede informado de ellas para prevenir lo que conviene antes [de] qe. llegue el casso de que tengamos una exclusiva sin reparo.

Espero me dirá V. Exc ${ }^{\mathrm{a}}$. lo q e. el Rey manda se execute, y Yo quedo a la $o b\left[\right.$ edienci]a de V. Exc ${ }^{\text {a }}$, $\operatorname{rog}[\mathrm{an}] \mathrm{do}$ a Dios, etc.».

16. Belluga en Madrid. Habiendo avisado al encargado de negocios español en Roma tener entregados al secretario de Estado los valiosos objetos de que era portador, Acquaviva reclama de Grimaldo el correspondiente recibo (septiembre, 1723). ${ }^{48}$

«Roma y Septiembre 18, de 1723.

Aunque el Sr. Card'. Belluga se ha servido dezirme en una de sus cartas haver puesto en manos de V. Exc ${ }^{a}$. los tres collares del Toysón y una llave de la

${ }^{48}$ AMAE, Santa Sede, leg. 284: Acquaviva a Grimaldo, Roma 18 septiembre 1723.

Hispania Sacra, LXII

125, enero-junio 2010, 243-265, ISSN: 0018-215-X 
Cámara del Rey qe. con orden de S. Mgd. entregué al Sr. Cardenal para ponerlos en poder de V. Exc ${ }^{\mathrm{a}}$., sin embargo no haviéndome V. Exc ${ }^{\mathrm{a}}$. avissado el recibo de estas al[h]ajas, suplico a V. Exc ${ }^{\mathrm{a}}$. mandar se me avisse su paradero, a fin $\mathrm{q}^{\mathrm{e}}$. por mi justificazión quede registrada en los papeles de este Ministerio.

Dios..., etc.». 